\title{
A new recognisable syndrome in three sibs with congenital heart disease, round face with depressed nasal bridge, short stature, and developmental retardation
}

\author{
TOHRU SONODA, SHOZO OHDO, HARUMICHI MADOKORO, \\ AND KEN-ICHI OHBA \\ Department of Pediatrics, Miyazaki Medical College, Miyazaki, Japan.
}

SUMMARY We report three sibs with congenital heart disease, round face with depressed nasal bridge, small mouth, short stature, developmental retardation, relatively dark skin, and high axial triradius. The chromosomes of the three patients were normal and the parents were unrelated, healthy, and of normal intelligence. The mother denied infections, drinking, drug intake, or exposure to known teratogenic agents during each pregnancy.

\section{Case reports}

\section{CASE 1}

The proband was born on 2.9.81 to unrelated and healthy parents. The mother had no previous history of spontaneous abortion or stillbirth. The facial appearance and skin colour of the parents were normal. The height of the father and mother was 170

Received for publication 17 August 1987.

Revised version accepted for publication 6 November 1987 $\mathrm{cm}$ and $153 \mathrm{~cm}$, respectively. The father and mother were both 25 years old at the time of birth. The birth weight of the proband was $2664 \mathrm{~g}$. At one month of age, heart murmurs were discovered at another institution and she was diagnosed as having a ventricular septal defect. She could lift her head at three months and began to walk alone at $\mathbf{1 7}$ months. At 18 months she began to speak a few words.

On physical examination in March 1983, height was $73.1 \mathrm{~cm}(-2.5 \mathrm{SD})$, weight $7.9 \mathrm{~kg}(-2.1 \mathrm{SD})$, and head circumference $46.0 \mathrm{~cm}$ (almost average). Physical findings included the following characteristics: dark skin, light brown hair, which is rare in Japanese, round face, small nose with flat nasal bridge and anteverted nostrils, and small mouth (fig 1). No abnormalities of the abdomen, external genitalia, or limbs were observed. Dermatoglyphic study showed three whorls and seven loops on the fingers. Atd angle in both palms was $70^{\circ}$ and there were no palmar transverse creases. DQ was 85 . The $G$ banded karyotype at the 550 band level was normal. The results of routine laboratory tests, including serum electrolytes, serum protein, immunoglobulins, blood and urine amino acids, T3, T4, and TSH levels, were all within normal limits.

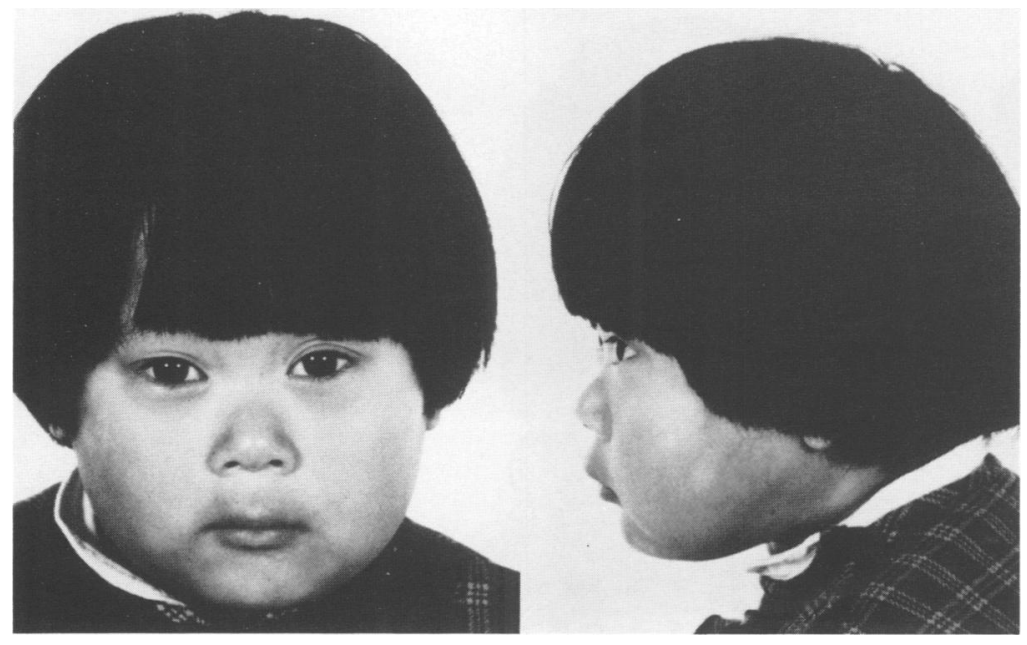

FIG 1 Case 1 at the age of three years eight months. 
At examination in May 1985, height was $88.6 \mathrm{~cm}$ ( $-2.3 \mathrm{SD}$ ), weight $13.2 \mathrm{~kg}$ (almost average), and head circumference $48.7 \mathrm{~cm}$ (almost average). DQ was about 45 . The heart murmur had almost disappeared, presumably because of spontaneous closure of the ventricular septal defect. Visual acuity and hearing were normal. There had been no seizures or neurological regression. Bone age was compatible with chronological age.

CASE 2

This brother of the proband was born on 3.7.83. Birth weight was $3042 \mathrm{~g}$. At birth, cyanosis was noted and a cardiac anomaly was suspected. Head control was attained at three months and he began to walk alone at 20 months. By the age of two, he could speak a few words.

At examination in July 1984, his height was $72 \cdot 7$ $\mathrm{cm}(-1.1 \mathrm{SD})$, weight $7.7 \mathrm{~kg}(-1.9 \mathrm{SD})$, and head circumference $44.5 \mathrm{~cm}(-1.4 \mathrm{SD})$. His skin was relatively dark, his hair was light brown, and his facial appearance closely resembled that of the proband (fig 2). A grade 4/6 systolic ejection murmur was heard at the second left intercostal space. Examination indicated that the heart murmur was caused by pulmonary valvular stenosis. No abnormality was detected in the abdomen, external genitalia, or limbs. Dermatoglyphic analysis showed normal palmar creases and four whorls and six loops on the finger tips. Atd angle was $90^{\circ}$ in the right palm and $80^{\circ}$ in the left. DQ was about 80 . A lymphocyte karyotype was normal and no fragile $\mathrm{X}$ chromosome was found.

When examined in May 1987, his height was $94 \cdot 3 \mathrm{~cm}$
(-1.3 SD), weight $15 \cdot 2 \mathrm{~kg}$ (almost average), and head circumference $49.7 \mathrm{~cm}$ (almost average). DQ was about 45 . Bone age corresponded with chronological age. Results of an endocrinological examination and plasma amino acid chromatogram proved to be entirely normal. There had been no seizures or neurological abnormality.

\section{CASE 3}

On 18.11.85 the mother had another son after an uneventful pregnancy. Birth weight was $2962 \mathrm{~g}$. Heart murmurs were discovered when he was three months old. When examined in May 1986, his height was $63.0 \mathrm{~cm}(-2.0 \mathrm{SD})$, weight $5.3 \mathrm{~kg}(-3.1 \mathrm{SD})$, and head circumference $41.5 \mathrm{~cm}(-1.7 \mathrm{SD})$. Skin colour, hair, and facial appearance closely resembled those of his two sibs (fig 3). A grade 2/6 systolic murmur was audible at the lower left sternal border, but it was assumed from the results of cardiac echography and other examinations that the murmur was innocent. Although ankyloglossia and hypospadias were noted, no abnormality was found in the abdomen and limbs. Dermatoglyphic studies showed five whorls and five loops. No palmar transverse crease was recognisable. Atd angle was $75^{\circ}$ in the right palm and $80^{\circ}$ in the left. A lymphocyte karyotype was $46, \mathrm{XY}$ and no fragile $\mathrm{X}$ chromosome was found.

When examined again in May 1987, his height was $73.9 \mathrm{~cm}(-2.2 \mathrm{SD})$, weight $8.8 \mathrm{~kg}(-1.7 \mathrm{SD})$, and head circumference $47 \cdot 4 \mathrm{~cm}$ (almost average). Although he was able to control his head six months after birth, at 18 months he was unable to walk alone or speak. DQ was about 30 . There had been

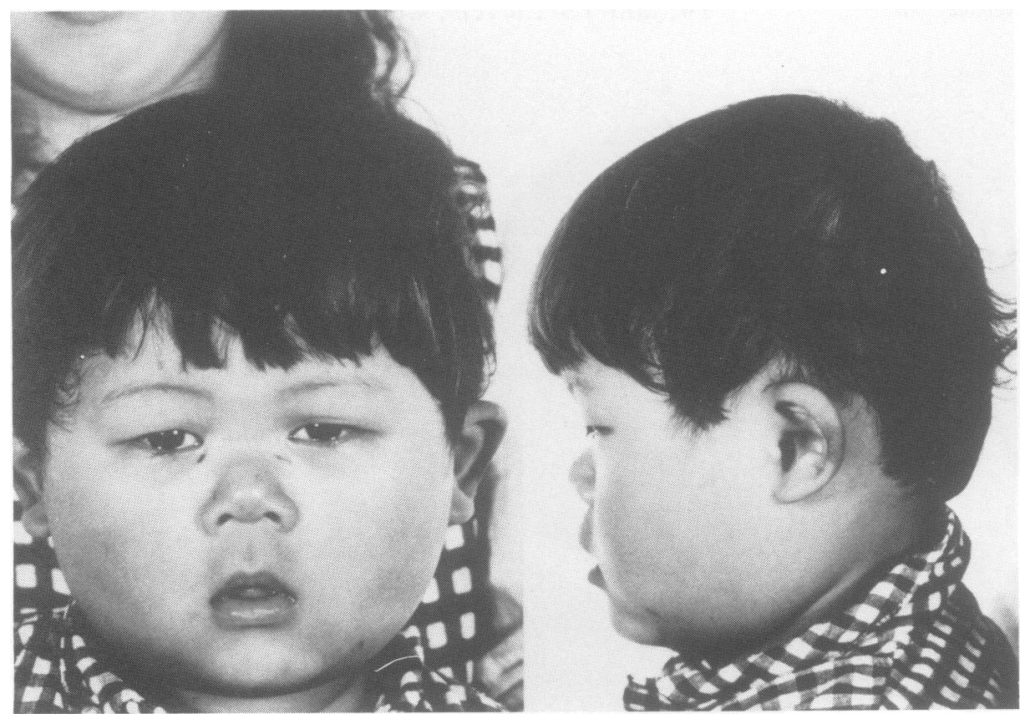

FIG 2 Case 2 at the age of 22 months. 

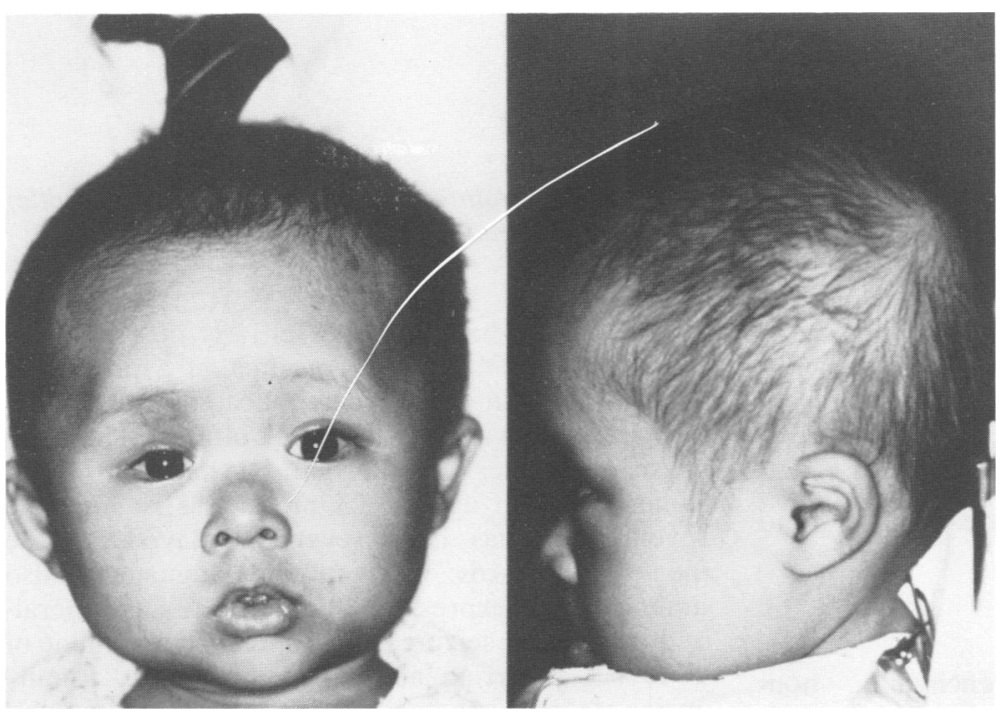

no seizures or neurological regression. Bone age was compatible with chronological age. Results of endocrinological tests and plasma amino acid chromatogram were normal.

\section{Discussion}

Characteristic findings in the cases described in this paper are summarised in the table. Among syndromes of growth and developmental retardation associated with congenital heart disease and midfacial hypoplasia, there are Williams' syndrome, Noonan's syndrome, Coffin-Lowry syndrome, fetal alcohol syndrome, effects of fetal trimethadione, warfarin, and hydantoin, ${ }^{1} 4 \mathrm{q}$ deletion, ${ }^{2}$ and cases

TABLE Clinical features in cases 1 to 3.

\begin{tabular}{llll}
\hline & Case 1 & Case 2 & Case 3 \\
\hline Psychomotor retardation & + & + & + \\
Short stature & + & - & + \\
Generalised dark skin & + & + & + \\
Light brown hair & + & + & + \\
Round face & + & + & + \\
Depressed nasal bridge & + & + & + \\
Small mouth & + & + & + \\
Congenital heart disease & + & + & + \\
High axial triradius & + & + & + \\
\hline
\end{tabular}

reported by Schinzel and Giedion. ${ }^{3}$ However, all these syndromes are clearly different from the one reported in this paper. As far as we could review published reports, we were unable to find other reports on cases having the same constellation of anomalies as described here.

Although the parents of our patients denied consanguinity, the ancestral families of both parents have lived for a long period in a rather small town, and it is difficult completely to rule out consanguinity. Autosomal recessive inheritance might be the most reasonable explanation for the aetiology of the anomalies, but other modes of inheritance could be present.

\section{References}

1 Smith DW. Recognizable patterns of human malformation. 3rd ed. Philadelphia: Saunders, 1982.

2 Jefferson RD, Burn J, Gaunt KL, Hunter S, Davison EV. A terminal deletion of the long arm of chromosome 4 $(46, X X, \operatorname{del}(4)(q 33))$ in a female infant with phenotypic features of Williams syndrome. J Med Genet 1986;23:474-7.

${ }^{3}$ Schinzel A, Giedion A. A syndrome of severe midface retraction, multiple skull anomalies, clubfeet, and cardiac and renal malformations in sibs. Am J Med Genet 1987;1:361-75.

Correspondence and requests for reprints to $\mathrm{Dr} T$ Sonoda, Department of Pediatrics, Miyazaki Medical College, 5,200 Kihara, Kiyotake-cho, Miyazaki 889-16, Japan. 